09.1

\title{
Исследование чувствительности микродискового лазера к изменению показателя преломления окружающей среды
}

\author{
(c) Н.В. Крыжановская ${ }^{1,2}$, И.А. Мельниченко ${ }^{1}$, А.С. Букатин ${ }^{2,3}$, А.А. Корнев ${ }^{2}$, Н.А. Филатов ${ }^{2}$, \\ С.А. Щербак ${ }^{1,2}$, А.А. Липовский ${ }^{2}$, А.С. Драгунова ${ }^{1,2}$, М.М. Кулагина $^{4}$, А.И. Лихачев ${ }^{4}$, \\ М.В. Фетисова ${ }^{2,5}$, И.В. Редуто ${ }^{5}$, М.В. Максимов ${ }^{2}$, А.Е. Жуков ${ }^{1}$ \\ ${ }^{1}$ Национальный исследовательский университет „Высшая школа экономики“, Санкт-Петербург, Россия \\ ${ }^{2}$ Санкт-Петербургский национальный исследовательский Академический университет им. Ж.И. Алфёрова РАН, \\ Санкт-Петербург, Россия \\ ${ }^{3}$ Институт аналитического приборостроения РАН, Санкт-Петербург, Россия \\ ${ }^{4}$ Физико-технический институт им. А.Ф. Иофффе РАН, Санкт-Петербург, Россия \\ ${ }^{5}$ Institute of Photonics, University of Eastern Finland, Joensuu, Finland \\ E-mail: nataliakryzh@gmail.com
}

Поступило в Редакцию 19 мая 2021 г.

В окончательной редакции 25 июня 2021 г.

Приято к публикации 25 июня 2021 г.

Исследована зависимость спектрального положения линии генерации микродискового лазера с квантовыми точками $\mathrm{InAs} / \mathrm{InGaAs} / \mathrm{GaAs}$ от показателя преломления водного раствора, в который погружен микролазер. Для микролазеров диаметром $10 \mu \mathrm{m}$, помещенных в водный раствор глюкозы, получена максимальная величина сдвига резонанса $9.4 \mathrm{~nm} / \mathrm{RIU}$.

Ключевые слова: микролазер, квантовые точки, моды шепчущей галереи, сенсор, детектирование.

DOI: 10.21883/PJTF.2021.19.51510.18878

В настоящее время существует необходимость поиска новых решений для создания миниатюрных оптических датчиков и сенсоров, способных работать в режиме реального времени $[1,2]$. Одним из направлений развития сенсорных элементов являются оптические микрорезонаторы с центральной или осевой симметрией (микросферы, микродиски, микрокольца), в которых осуществляется эффективная локализация электромагнитного поля в трех направлениях [3]. В таких резонаторах формируются высокодобротные моды шепчущей галереи (МШГ), возникающие за счет полного внутреннего отражения электромагнитных волн от стенок резонатора. Известно, что микрорезонаторы с МШГ обладают высокой чувствительностью к изменениям и возмущениям параметров окружающей среды вблизи их поверхности [4], что позволяет использовать их в качестве сенсоров, отслеживающих изменения окружающей среды. Один из механизмов детектирования с помощью МШГ-микрорезонатора основан на измерении сдвига длины волны резонанса, вызванного изменением показателя преломления окружающей среды. Сенсоры на основе МШГ-микролазеров имеют ряд преимуществ перед аналогами на основе пассивных МШГ-микрорезонаторов благодаря тому, что они сами являются источником излучения с большей интенсивностью и узкой спектральной линией и не требуют внешнего лазера [5]. Кроме того, пороговый характер лазерной генерации способен увеличить чувствительность к слабым изменениям окружающей среды. В настоящее время уже реализованы микродисковые лазеры на основе кван- товых точек InAs/InGaAs/GaAs, способные работать в непрерывном режиме при оптической накачке в водной среде [6]. Кроме того, такие микролазеры могут быть успешно интегрированы с кремниевой подложкой [7], с детектором лазерного излучения [8], а также демонстрируют скорость передачи данных до $10 \mathrm{~Gb} / \mathrm{s}$ при низком энергопотреблении [9].

Детектирование водных растворов биологического происхождения подразумевает возможность определения малых изменений показателя преломления. Несмотря на высокую привлекательность полупроводниковых МШГ-лазеров для использования в качестве детектирующих элементов, в настоящее время практически отсутствуют работы, в которых были бы выполнены оценки сдвига МШГ резонанса при изменении показателя преломления окружающей среды. В настоящей работе впервые проведена теоретическая оценка сдвига МШГ резонанса и выполнено экспериментальное исследование спектрального положения линии лазерной генерации InAs/InGaAs/GaAs-квантовых точек микролазера в зависимости от показателя преломления водной среды, в которую помещался микролазер.

Полупроводниковая гетероструктура была выращена методом молекулярно-пучковой эпитаксии на нелегированной подложке GaAs (100). После осаждения буферного слоя GaAs выращивался слой $\mathrm{Al}_{0.98} \mathrm{Ga}_{0.02} \mathrm{As}$ толщиной $400 \mathrm{~nm}$. Активная область помещалась в волноводный слой $\mathrm{GaAs}(220 \mathrm{~nm})$ и представляла собой пять слоев квантовых точек InAs/ $\mathrm{In}_{0.15} \mathrm{Ga}_{0.85} \mathrm{As}$, разделенных спейсерами GaAs толщиной $30 \mathrm{~nm}$. Спектраль- 

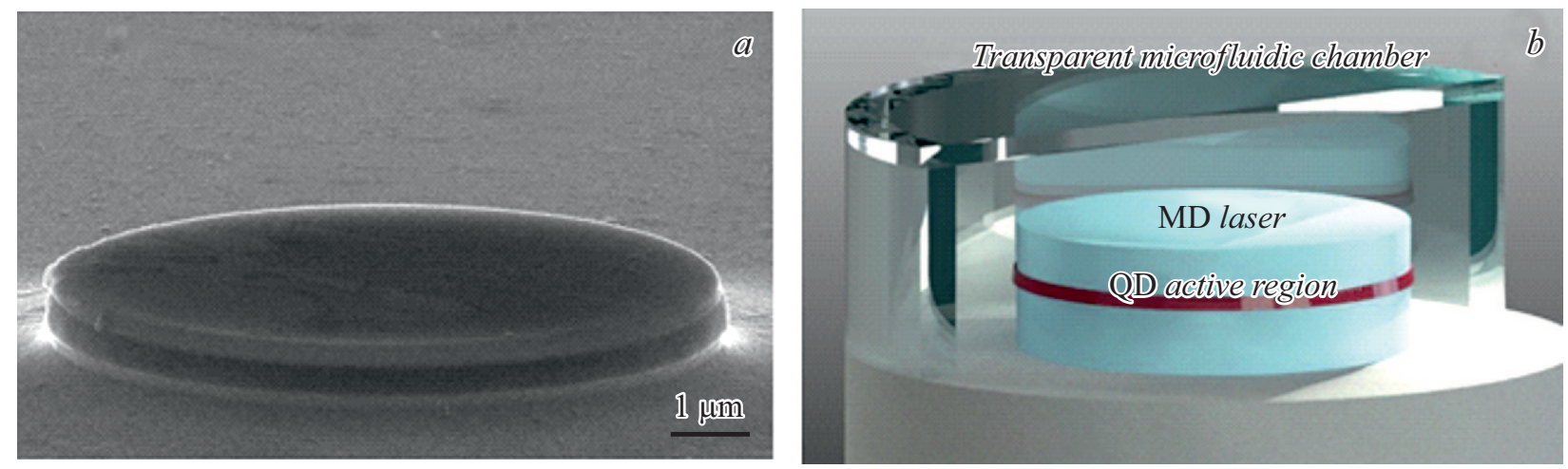

Рис. 1. Изображение микролазера, полученное с помощью сканирующего электронного микроскопа JSM 7001F (JEOL, Япония) (a), и схематическое изображение микролазера, размещенного в прозрачной камере $(b)$.

ное положение основного перехода квантовых точек располагается вблизи $1.3 \mu \mathrm{m}$ при комнатной температуре. Микродисковые резонаторы были сформированы методом фотолитографии и ионно-лучевого травления $\left(\mathrm{Ar}^{+}\right)$. Были исследованы резонаторы диаметром 7-10 $\mu \mathrm{m}$ (рис. $1, a$ ). Слой $\mathrm{Al}_{0.98} \mathrm{Ga}_{0.02} \mathrm{As}$ был преобразован в оксид $(\mathrm{AlGa})_{x} \mathrm{O}_{y}$ методом селективного окисления для реализации оптического ограничения со стороны подложки, препятствующего утеканию моды в подложку. После этого методом атомно-слоевого осаждения микродиски были покрыты слоем диоксида кремния толщиной $5 \mathrm{~nm}$ для защиты поверхности лазера при погружении в водные растворы. Далее образец с микролазерами помещался в прозрачную ячейку из полидиметилсилоксана, снабженную микроканалами, через которые ее можно было заполнять жидкостью (рис. $1, b)$. В качестве тестовых жидкостей были использованы водные растворы хлорида натрия $(\mathrm{NaCl})$ и глюкозы $\left(\mathrm{C}_{6} \mathrm{H}_{12} \mathrm{O}_{6}\right)$, для которых хорошо известны зависимости показателя преломления от концентрации.

Исследования спектров излучения микролазеров выполнялись при комнатной температуре при оптической накачке лазером YLF: Nd $(527 \mathrm{~nm})$, работающим в непрерывном режиме, с использованием оптического конфокального микроскопа (Ntegra Spectra, NT-MDT). Для фокусировки лазерного пятна диаметром $\sim 1 \mu \mathrm{m}$ на поверхность микродискового лазера использовался объектив $\times 100$ (Mitutoyo, $N A=0.5$ ). Этот же объектив применялся для сбора излучения микролазера, которое детектировалось с помощью монохроматора MS5204і (SOL Instruments) и многоканального охлаждаемого InGaAs-детектора iDUS (Andor). Спектральное разрешение установки составило $16 \mathrm{pm}$. Спектры излучения микролазеров исследовались вблизи порога лазерной генерации для предотвращения перегрева образцов излучением лазера накачки. Полуширина линии излучения вблизи порога генерации, т. е. при близкой к нулю мощности излучения, составила около $60 \mathrm{pm}$, что позволяет выполнить оценку добротности резонатора $(Q \sim \lambda / \Delta \lambda)$ и сделать вывод, что добротность не хуже чем $2 \cdot 10^{4}$.
С помощью численного моделирования был выполнен расчет спектрального положения резонанса микродискового лазера при изменении показателя преломления окружающей среды. Для анализа МШГ в микродисковых резонаторах использовалось численное моделирование методом конечных элементов в программном пакете COMSOL Multiphysics. Были рассмотрены МШГ первых трех радиальных порядков микродиска диаметром $8 \mu \mathrm{m}$ на основе $\mathrm{GaAs}$, длина волны которых лежит вблизи $1.3 \mu \mathrm{m}$ (вставки к рис. 2, a). Результаты расчета показали заметный длинноволновый сдвиг длины волны МШГ резонанса при изменении показателя преломления окружающей среды в интервале $1.32-1.35$, причем полученная зависимость имеет линейный характер (рис. 2,a). Величина сдвига возрастает от $6 \mathrm{~nm} / \mathrm{RIU}$ (refractive index unit) для моды с нулевым радиальным порядком до $9.7 \mathrm{~nm} / \mathrm{RIU}$ для моды со вторым радиальным порядком. Более сильная чувствительность мод старших радиальных порядков к изменению показателя окружающей среды связана с тем, что они менее локализованы внутри резонатора, область спадающего поля за границу резонатора у них больше и соответственно влияние окружающей среды также сильнее [10]. Отметим, что в соответствии с расчетами рассматриваемое малое изменение показателя преломления окружения не оказывает влияния на добротность МШГ [11].

На основе деионизированной воды были приготовлены растворы соли $(\mathrm{NaCl})$ с концентрацией 0-20\% и глюкозы $\left(\mathrm{C}_{6} \mathrm{H}_{12} \mathrm{O}_{6}\right)$ с концентрацией $0-30 \%$, что для длины волны $\sim 1.3 \mu \mathrm{m}$ соответствует линейному изменению коэффициента преломления $n=1.32-1.37$ (вставка к рис. 3,a) [12].

При увеличении концентрации соли ширина линии резонанса не меняется, что свидетельствует о неизменности добротности и уровня оптических потерь (рис. $2, b)$. Спектральное положение резонансной длины волны сдвигается в длинноволновую сторону линейно (рис. $3, a$ ) в зависимости от концентрации $\mathrm{NaCl}$ в растворе. По наблюдаемой величине сдвига можно оценить чувствительность микролазера к изменению показателя 

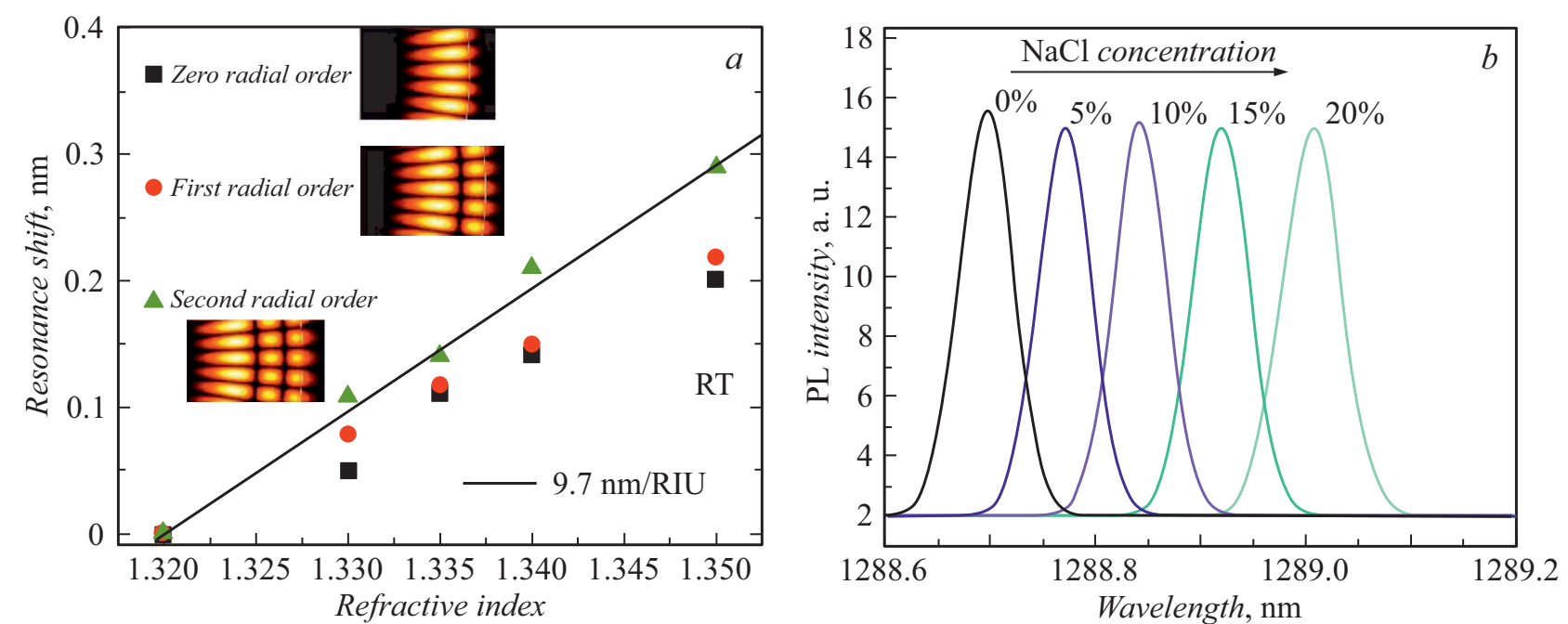

Рис. 2. $a-$ результаты расчета спектрального положения МШГ резонансов микродискового лазера диаметром $8 \mu \mathrm{m}$ в зависимости от показателя преломления окружающей среды для случаев нулевого (квадраты), первого (кружки) и второго (треугольники) радиального порядка моды. Линия соответствует чувствительности $9.7 \mathrm{~nm} / \mathrm{RIU}$. На вставках — рассчитанные распределения электрического поля рассматриваемых МШГ в латеральной плоскости микролазера. $b-$ спектры фотолюминесценции микролазера диаметром $10 \mu \mathrm{m}$, полученные при различной концентрации водного раствора соли $(b)$.
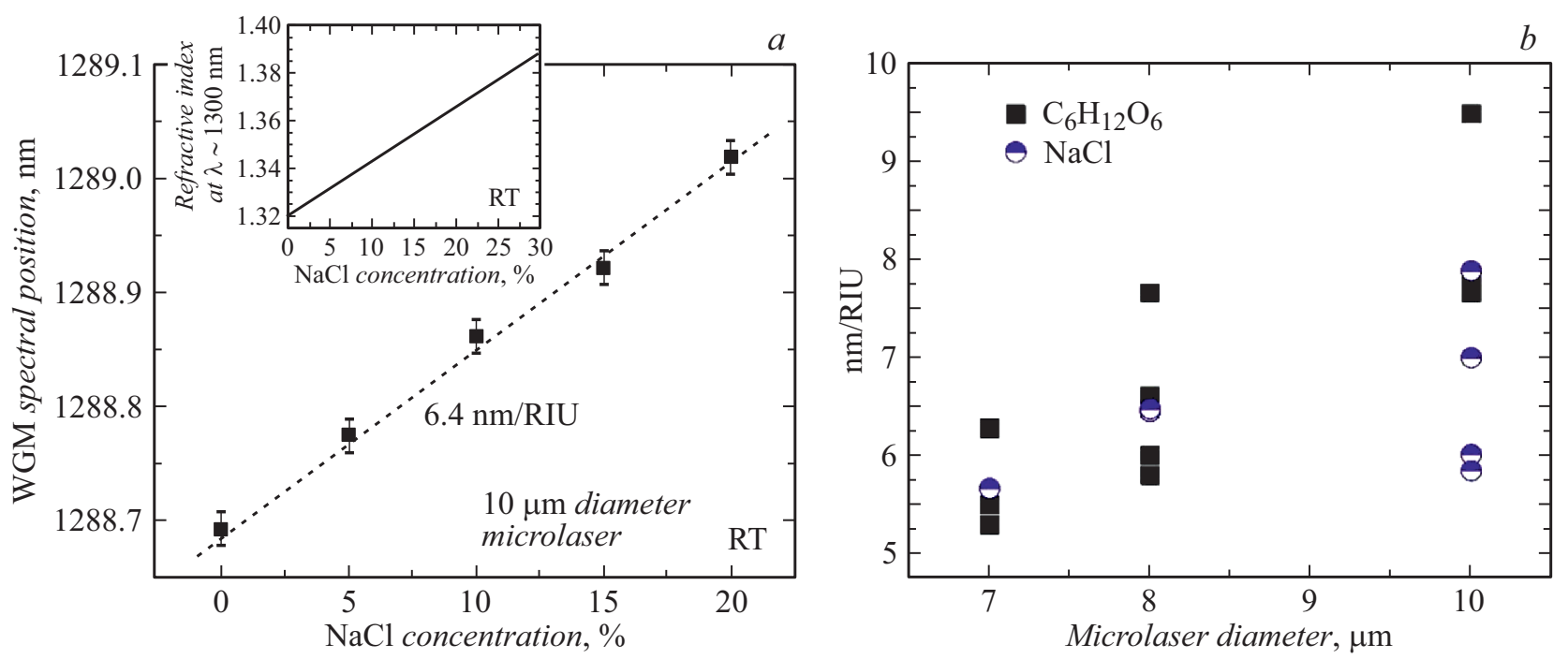

Рис. 3. $a-$ зависимость спектрального положения резонанса микролазера диаметром $10 \mu \mathrm{m}$ от концентрации водного раствора соли (на вставке - зависимость показателя преломления от концентрации водного раствора соли); $b$ - значения чувствительности микролазеров диаметром 7-10 $\mu \mathrm{m}$ к изменению показателя преломления раствора для водных растворов соли (кружки) и глюкозы (квадраты).

преломления как $6.4 \mathrm{~nm} / \mathrm{RIU}$, что хорошо согласуется c данными численного расчета для моды нулевого радиального порядка.

Также были выполнены измерения чувствительности для различных мод микролазеров, в том числе для не участвующих в лазерной генерации (боковых) мод, интенсивность которых на несколько порядков меньше, чем у лазерной моды. Полученные значения для микролазеров диаметром 7-10 $\mathrm{m}$, погруженных в приготовленные растворы соли и глюкозы, представлены на рис. $3, b$. Наблюдается разброс значений чувствитель- ности от 5.5 до $9.4 \mathrm{~nm} / \mathrm{RIU}$, связанный с наличием в спектре мод различного радиального порядка.

Таким образом, в результате исследования показана возможность использования микролазеров дисковой геометрии с активной областью на основе квантовых точек InAs/InGaAs в качестве универсальных биохимических сенсоров, способных работать в жидких средах. Получено максимальное значение чувствительности длины волны микролазера к изменению показателя преломления $9.4 \mathrm{~nm} / \mathrm{RIU}$. Учитывая, что полуширина линии излучения составляет около 60 pm, мы можем заключить, 
что возможно детектирование минимального изменения показателя преломления на величину 0.006. Полученное значение спектрального сдвига позволяет судить о возможности создания биосенсоров, пригодных для детектирования таких веществ, как бычий сывороточный альбумин (BSA) или человеческий $\operatorname{IgG}$ (Human $\operatorname{IgG}$ ), в концентрациях порядка $\mathrm{pg} / \mathrm{ml}$ [13].

\section{Благодарности}

Электронно-микроскопические исследования выполнены с использованием оборудования федерального ЦКП „Материаловедение и диагностика в передовых технологиях ${ }^{6}$.

\section{Финансирование работы}

Работа выполнена при поддержке Российского фонда фундаментальных исследований (проект № 20-0200334), расчеты проведены в рамках Программы фундаментальных исследований НИУ ВШЭ. А.С. Букатин, Н.А. Филатов и А.А. Корнев благодарят Министерство науки и высшего образования РФ (проект № 0791-2020-0006).

\section{Конфликт интересов}

Авторы заявляют, что у них нет конфликта интересов.

\section{Список литературы}

[1] S. Lin, K.B. Crozier, ACS Nano, 7(2), 1725 (2013). DOI: $10.1021 / \mathrm{nn} 305826 \mathrm{j}$

[2] S.M. Borisov, O.S. Wolfbeis, Chem. Rev., 108 (2), 423 (2008). DOI: $10.1021 / \mathrm{cr} 068105 \mathrm{t}$

[3] J. Su, Sensors, 17 (3), 540 (2017). DOI: 10.3390/s17030540

[4] L. He, Ş.K. Özdemir, L. Yang, Laser Photon. Rev., 7 (1), 60 (2013). DOI: 10.1002/lpor.201100032

[5] Y.C. Chen, X. Tan, Q. Sun, Q. Chen, W. Wang, X. Fan, Nature Biomed. Eng., 1 (9), 724 (2017). DOI: $10.1038 / \mathrm{s} 41551-017-0128-3$

[6] M.V. Fetisova, N.V. Kryzhanovskaya, I.V. Reduto, E.I. Moiseev, S.A. Blokhin, K.P. Kotlyar, S.A. Scherbak, A.A. Lipovskii, A.A. Kornev, A.S. Bukatin, M.V. Maximov, A.E. Zhukov, J. Phys.: Conf. Ser., 1124 (5), 051007 (2018). DOI: $10.1088 / 1742-6596 / 1124 / 5 / 051007$

[7] А.Е. Жуков, Э.И. Моисеев, А.М. Надточий, А.С. Драгунова, Н.В. Крыжановская, М.М. Кулагина, А.М. Можаров, С.А. Кадинская, О.И. Симчук, Ф.И. Зубов, М.В. Максимов, Письма в ЖТФ, 46 (16), 3 (2020). DOI: $10.21883 /$ PJTF.2020.16.49844.18354

[8] Н.В. Крыжановская, А.М. Надточий, Э.И. Моисеев, А.Е. Жуков, А.А. Харченко, С.А. Минтаиров, Н.А. Калюжный, М.М. Кулагина, М.В. Максимов, Письма в ЖТФ, 46 (13), 7 (2020). DOI: 10.21883/PJTF.2020.13.49582.18301

[9] N.V. Kryzhanovskaya, E.I. Moiseev, F.I. Zubov, A.M. Mozharov, M.V. Maximov, N.A. Kalyuzhnyy, S.A. Mintairov, Yu.A. Guseva, M.M. Kulagina, S.A. Blokhin, Yu. Berdnikov, A.E. Zhukov, J. Appl. Phys., $126(6), 063107$ (2019). DOI: $10.1063 / 1.5108556$
[10] I. Reduto, M. Fetisova, N. Kryzhanovskaya, K. Kotlyar, A. Raskhodchikov, S. Scherbak, Yu. Guseva, A. Lipovskii, M. Maximov, A. Zhukov, J. Opt. Soc. Am. B, 36 (8), 2285 (2019). DOI: 10.1364/JOSAB.36.002285

[11] A.V. Raskhodchikov, S.A. Scherbak, N.V. Kryzhanovskaya, A.E. Zhukov, A.A. Lipovskii, J. Phys.: Conf. Ser., 1124 (5), 051031 (2018). DOI: 10.1088/1742-6596/1124/5/051031

[12] https://refractiveindex.info/

[13] Z. Guo, Y. Qin, P. Chen, J. Hu, Y. Zhou, X. Zhao, Small, 16 (26), 2000239 (2020). DOI: 10.1002/smll.202000239 